\title{
Cultural tightness-looseness and national innovativeness: impacts of tolerance and diversity of opinion
}

\author{
Carsten Deckert $^{2^{*}}$ and Rahel M. Schomaker ${ }^{1}$
}

\author{
${ }^{*}$ Correspondence: \\ carsten.deckert@hs- \\ duesseldorf.de \\ ${ }^{2}$ Hochschule Duesseldorf \\ University of Applied \\ Sciences (HSD), Düsseldorf, \\ Germany \\ Full list of author information \\ is available at the end of the \\ article
}

\begin{abstract}
The links between innovativeness as a driver of economic performance, and the determinants of innovativeness have been investigated by management scholars and economists for decades, focusing mostly on "hard factors" as investment in research and development, or education. Focusing on a relatively neglected, but in times of globalization even more important aspect, the influence of cultural characteristics on innovativeness, we apply different econometric models to test for links between cultural tightness and looseness on the one hand, and national innovativeness on the other hand. We find that cultural tightness - in the sense of homogenous and intolerant societies—-has a negative link to national innovativeness, while cultural looseness - in the sense of tolerant and diverse societies_-displays a positive link to national innovativeness.
\end{abstract}

Keywords: Innovation, National innovativeness, Culture, Tolerance, Diversity of opinion

\section{Introduction}

The connection between innovation and economic performance has been discussed in management literature as well as economic theory for several decades, with the overall conclusion that the economic performance of countries not least depends on their innovativeness (Freeman, 1996, 2002; Porter, 1990; Verspagen, 2006). Given this relevance of innovativeness for societies and economies, potential driving factors have been examined, with human capital, property rights, education, research institutions being among the most extensively used explanatory factors, even if they explain only a part of the variance in innovativeness among countries (Taylor, 2016). Thus, we focus on an additional group of potential explanatory factors, cultural characteristics, taking stock of the analysis of Landes (2002: 516) that states that "culture makes all the difference" when it comes to economic development and, hence, innovativeness as it influences the creation and dissemination of knowledge in a country.

Putting national innovativeness center stage, the paper at hand focuses on cultural characteristics as potential driving factors, in detail the concept of tightness and

(c) The Author(s) 2022. Open Access This article is licensed under a Creative Commons Attribution 4.0 International License, which permits use, sharing, adaptation, distribution and reproduction in any medium or format, as long as you give appropriate credit to the original author(s) and the source, provide a link to the Creative Commons licence, and indicate if changes were made. The images or other third party material in this article are included in the article's Creative Commons licence, unless indicated otherwise in a credit line to the material. If material is not included in the article's Creative Commons licence and your intended use is not permitted by statutory regulation or exceeds the permitted use, you will need to obtain permission directly from the copyright holder. To view a copy of this licence, visit http:// creativecommons.org/licenses/by/4.0/. 
looseness as developed by Gelfand et al., (2011a, 2011b), and Uz (2015a, 2015b). The paper proceeds as follows: after this introduction and short considerations of the concepts of innovativeness and tightness/looseness, we empirically test our hypotheses. Applying different econometric methods, we find that tightness, understood as low tolerance, isolation, and a homogenous society, affects national innovativeness negatively, while looseness in the sense of tolerant and diverse societies has a positive influence on national innovativeness. After a reflection of these findings against the backdrop of current research, we draw some policy recommendations.

\section{Literature review}

\section{National innovativeness}

Innovativeness can be defined based on approaches that focus on the adoption of new ideas in a social system, as emphasized by diffusion theory (e.g., Rogers, 2003), or 'the quality of being innovative' (Kumar, 2014: 3; for details on different definitions of innovativeness see Deckert \& Schomaker, 2018). The latter one constitutes the approach that is taken in this study. Thus, innovativeness comprises conditions which "need to be created for a system to continuously-not just intermittently-induce innovations" and "which can relate to individuals, companies, networks and teams and to whole societies as a multidimensional construct with many levels" (Trantow et al., 2011: 3).

Related to the idea by Trantow et al. (2011), national innovativeness as being focused on in our study can also be understood as innovative capacity (Furman et al., 2002; Porter \& Stern, 2001), propensity to innovate (Williams \& McGuire, 2010) or innovation performance (Adam, 2013; Gault, 2014). In other words, it is "a country's potential [...] to produce a stream of commercially relevant innovations" (Porter \& Stern, 2001: 29), and "the ability of a country to produce and commercialize a flow of innovative technology over the long term" (Furman et al., 2002, p. 899). Not only the outcome in terms of realized or diffused innovations matter, but also "the fundamental conditions, investments and policy choices that create the environment for innovation in a particular location" (Porter \& Stern, 2001: 23). National innovativeness depends on knowledge and technology creation and diffusion, thus the support provided by national institutions as research policies, or "networks of related actors and institutions such as entrepreneurs, private enterprises with professional research and development facilities, public research institutes and universities" (Deckert \& Schomaker, 2018). These systems are typically referred to as National Innovation Systems (NIS) or National Systems of Innovation (NSI), and focused on in this paper (Freeman, 1995; Freeman \& Soete, 1997; Lundvall, 1999, OECD, 1997).

\section{Cultural factors-the tightness-looseness concept}

The concept of cultural tightness-looseness as cultural traits was introduced in anthropology to classify different forms of traditional societies along a continuum (Pelto, 1968). Later, Triandis (1989) proposed the concept as an important cultural dimension of modern societies, complementing other cultural features or characteristics as used for classification of cultures before.

Tightness-looseness in the cultural context is defined by Witkin and Berry (1975: 16) as the "degree of hierarchical structure among sociocultural elements in a society" 
and addresses issues of pressure to conform and social control. According to Triandis (1989: 511), "ingroup members behave according to the ingroup norms" in tight cultures, whereas in loose cultures either norms are unclear or deviations from norms are tolerated. In a similar vein, Carpenter (2000: 41) argues that in tight cultures "norms are explicit and stringently enforced", while in loose cultures "behaviors that constitute proper behavior are relatively flexible and more freely chosen" and "deviations from norms are more tolerated". Finally, Gelfand (2012: 420) defines tight societies as "societies that have strong norms and a low tolerance for deviant behavior" and loose societies as "societies that have weak norms and a high tolerance for deviant behavior".

While cultural dimensions for modern societies typically focus on certain values (e.g., Hofstede, 2003; House et al., 2004), the concept of tightness-looseness focusses on social or cultural norms (Gelfand, 2012; Gelfand \& Jackson, 2016), i.e., "socially agreedon standards for behavior" (Gelfand et al., 2017: 800). Gelfand et al. (2006) distinguish between two key components of tightness-looseness in this regard: first, the strength of social norms as manifested by their number and clarity, and, second, the degree of sanctioning as revealed by the tolerance of deviation from social norms.

Tight societies are usually more homogenous and isolate themselves from external cultural influences (Triandis, 1989). Thus, on average, loose cultures are seen as more creative as they are more open to different ideas, different people and different cultural influences (Gelfand, 2018). Triandis (1989) proposes a weak linear relation of tightness to collectivism. As individualism is usually associated with creativity and innovation (Lubart, 2010), loose societies should also be more creative due to a higher level of individualism. Gelfand et al. (2006) propose that individuals in loose societies usually have a greater promotion focus ${ }^{1}$ and a greater preference of the cognitive style of innovators. ${ }^{2}$ Furthermore, organizations in loose societies have a tendency towards experimentation, trial and error as well as a culture of lower constraints.

Hence, cultural tightness and looseness, respectively, exhibit close relations not only to individual behavior, but also to cultural and socio-economic institutions (Gelfand et al., 2011a: 1102). According to North (1991: 97) institutions are "the humanly devised constraints that structure political, economic and social interaction". While they can be differentiated in more formal and informal institutions, there is some evidence that social, political and economic institutions are not independent of each other, and a result of societal action and preferences: "Economic institutions, and institutions more broadly, are endogenous; they are, at least in part, determined by society, or a segment of it. Consequently, the question of why some societies are much poorer than others is closely related to the question of why some societies have much 'worse economic institutions' than others" (Acemoglu et al., 2005: 389). Thus, Acemoglu and Robinson (2013) argue

\footnotetext{
${ }^{1}$ For the self-regulation of motivational states, Higgins $(1997,1998)$ proposes a concept of promotion focus and prevention focus. The promotion focus is characterized by a tendency to approach positive outcomes as expressed in a preference to look for hits and avoid errors of omission (Higgins, 1997). It is concerned with "accomplishments, hopes, and aspirations" (Higgins, 1998: 17). The prevention focus is characterized by a tendency to avoid negative outcomes, which is expressed in a preference to avoid misses and errors of commission (Higgins, 1997). It is concerned with "safety, responsibility, and obligations" (Higgins, 1998: 17).

${ }^{2}$ Kirton (1989) distinguishes between the cognitive styles of adaptors and innovators. While adaptors usually "accept the generalized theories, policies, customary viewpoints or [...] 'paradigms"' of a given problem, innovators "detach the problem from its cocoon of accepted thought, to reconstruct the problem and its attendant paradigm while in the pursuit of a solution" (Kirton, 1989: 6).
} 
that societal and political institutions of a country shape its economic institutions. Centralized and pluralistic political institutions such as secure property rights for all citizens, equal opportunities and checks of power set incentives for innovation, as they guarantee functioning markets and foster the market entry of new products, processes or business models. Following this argument, tightness and looseness as factors being correlated to societal values and expressed political preferences, necessarily influence economic institutions via elections, the composition of organizations and organizational behavior.

One important chain of transmission is related to cultural factors. Based on categories from the GLOBE study, Schomaker and Deckert (2020) specify cultural dimensions that influence political institutions and therewith national innovativeness. These dimensions are Power Distance, In-Group Collectivism and Performance Orientation (Deckert \& Schomaker, 2018). From these, Power Distance ${ }^{3}$ and In-Group Collectivism ${ }^{4}$ show a close connection to cultural tightness, as typically high degrees of both of these indicators are related to severe restrictions in personal freedom. A high Power Distance implies stronger tendencies to unequal power distribution, stable and scarce power bases, high levels of corruption, unequal opportunities for the members of society and limited upward social mobility (House et al., 2004). Power Distance is negatively correlated with innovativeness, pluralistic institutions seem to be conducive to innovations while exclusive institutions are detrimental to innovations.

The impact of In-Group Collectivism may be explained through the degree of exclusiveness and clanism in a society that may lead to a solidification of the status quo, as these factors help existing elites to maintain and consolidate their position (Deckert \& Schomaker, 2018). Thus, the high correlation between In-Group Collectivism and a high degree of cultural tightness makes it plausible to assume the same effects for the latter one (Triandis, 1989).

Based on these considerations, it can be derived that loose societies due to individual behavior as well as their institutional framework depict a higher level of national innovativeness, while tight groups and societies-and therewith the respective economies-show lower levels of innovative behavior and enabling institutions, and therewith national innovativeness.

\section{Operationalization of cultural tightness-looseness}

As for an operationalization of the concept of cultural tightness-looseness as delineated above, two approaches are discussed in literature: first, the tightness score of Gelfand et al., (2011a, 2011b), and, second, the cultural tightness-looseness (CTL) index of Uz (2015a, 2015b).

For constructing the respective scores, Gelfand et al. (2011a) collected primary data from 6960 individual respondents in 33 countries. ${ }^{5}$ For doing so, a survey of six questions was used, tackling the number and clarity of social norms, agreement on social norms, freedom of behavior, degree of sanctioning and compliance to social norms.

\footnotetext{
${ }^{3}$ Power Distance is defined as the "degree to which members of a collective expect power to be distributed equally" (House et al., 2002, p. 6).

${ }^{4}$ In-Group Collectivism is defined as the "degree to which individuals express pride, loyalty, and cohesiveness in their organizations and families" (House et al., 2002, p. 6).

5 For a full country list see Appendix.
} 
The items are rated on a Likert scale with six response levels and ranked (Gelfand et al., 2011b). ${ }^{6}$ The higher a country is ranked on the tightness score, the higher its cultural tightness is.

Uz (2015a) applies the concept of variance to determine cultural tightness-looseness, as tight cultures are usually homogenous (Triandis, 1989, 1994), with less variation across individuals in a tight society (Gelfand et al., 2006). For constructing the respective indicator, she uses secondary data from the 4th wave of the World Values Survey (WVS) as conducted in 2000, and calculates the standard deviation of selected items from this survey. The higher the standard deviation of a country, the looser the respective society is $(\mathrm{Uz}, 2015 \mathrm{a})$.

From this point of departure, she calculates three indices (Uz, 2015a, 2015b): The domain-specific index contains data from the Morally Debatable Behaviors Scale (MDBS) of 68 countries, ${ }^{7}$ which measures the tolerance for moral deviations, i.e., acceptability of prostitution, abortion, divorce, euthanasia, and suicide. The domain-general index calculates the mean of the standard deviations of all 124 items of the WVS of 64 countries. The combination index categorizes items of 65 countries according to the domains of work, family and religion and determines a score of the standard deviation of the domains. ${ }^{8}$

Uz (2015a) proposes the application of the combination index as it conflates the advantages of the other two indices (domain-specific index and domain-general index). The combination index has great variety of values as well as great validity, and its weights of items is independent of the number of survey questions in the respective category.

Hence, the two indicators as discussed measure the same concept-tightness-looseness-applying different methodologies and with a different message: While in the tightness score of Gelfand et al. (2011a) high values indicate for tight cultures, in the cultural tightness-looseness index combination index of Uz (2015a), high values stand for loose societies.

While the concept of tightness and looseness often is discussed separately from other concepts of cultural dimensions typically used in empirical work (see e.g., Deckert \& Schomaker, 2018), interrelations between different approaches can be identified. Overall, the tightness score of Gelfand et al. (2011b) has a statistically significant, negative correlation to individualism and a statistically significant, positive correlation to Power Distance as used by Hofstede (2003), with the Hofstede-dimension of Individualism being positively related to innovativeness, the dimension of Power Distance being negatively related to innovativeness (Deckert \& Nyssen Guillén, 2017). The indicator of Uz (2015a)

\footnotetext{
${ }^{6}$ In detail, the following questions were asked: 1 . There are many social norms that people are supposed to abide by in this country. 2. In this country, there are very clear expectations for how people should act in most situations. 3. People agree upon what behaviors are appropriate versus inappropriate in most situations this country. 4. People in this country have a great deal of freedom in deciding how they want to behave in most situations. (Reverse coded) 5 . In this country, if someone acts in an inappropriate way, others will strongly disapprove. 6. People in this country almost always comply with social norms. The index was tested for reliability and validity It was examined if people have low variability in their perceptions of the strength of social norms and the degree of tolerance for deviance in their respective country, if there is significant between-nation variance in the construct, and if country-level means are reliable at the culture level. For a detailed description of the methodology used by Gelfand et al. (2011a) see the supplemental material of the respective article (Gelfand et al., 2011b)

7 For a full country list see Appendix.

${ }^{8}$ For a detailed overview of the three indexes developed by Uz (2015a), see the table in the Appendix of the paper at hand, and the supplemental material of the respective article (Uz 2015b).
} 
is negatively correlated to conformity, and, as will be discussed in the following, positively correlated to innovation as measured by the Global Innovation Index (Uz, 2015b).

Thus, our empirical strategy is based on the following hypotheses as derived from theoretical considerations how tightness and looseness may affect innovativeness. Our working hypothesis is that cultural tightness has a negative relation to national innovativeness, and conversely cultural looseness has a positive relation to national innovativeness. Based on this, we scrutinize the hypotheses as follow in our empirical tests:

H1 The tightness score (TS) of Gelfand et al. (2011a) has a negative relation to national innovativeness.

H2 The cultural tightness-looseness combination index (CTL_C) of Uz (2015a) has a positive relation to national innovativeness.

\section{Data and methodology}

With a view on the data available, we decided to apply a multi-step research design: firstly, we test the different measures for cultural tightness/looseness and the measure for innovativeness as delineated above for correlations both of the ranks as well as the values.

Secondly, we apply a hierarchical cluster analysis to group together countries that are "close" to one another in terms of cultural looseness on the one hand, and innovativeness on the other hand. Thus, this technique allows us to detect groups by proceeding sequentially from tighter, less inclusive clusters to larger more inclusive clusters (Bridges, 1966).

Thirdly, taking into consideration that the results may be affected by potential endogeneity issues, therewith using this approach only supplementary, we follow up with the theoretical discussion of potential causal links between cultural factors and innovativeness. Due to methodological and data limitations, in empirical studies, these tests are hardly to be found (e.g., Taylor, 2016). Nonetheless, being aware of the existing restrictions, we apply regression models to test in how far cultural characteristics could be interpreted as drivers of innovativeness.

As the measure of innovativeness on the country level, the values of the Global Innovation Index (GII) for 2019 are used, as there is already sound evidence for the indicator being a suitable measure for innovativeness in the context of cultural influences (e.g., Deckert \& Nyssen Guillén, 2017; Deckert \& Schomaker, 2018). The Global Innovation Index is calculated as the simple average of two sub-indexes, the Innovation Input Sub-Index and the Innovation Output Sub-Index. While the first sub-indicator comprises facilitators of innovation activities such as human capital and infrastructure, the second sub-indicator scrutinizes the results of innovation activities (Cornell University, INSEAD and WIPO, 2019).

Furthermore, we use data from the Innovation Union Scoreboard (IUS)/European Innovation Scoreboard (EIS) for 2013 as a robustness check. The IUS/EIS is published annually by the European Commission and measures the innovativeness of the EU member states with an index of about 25 indicators (Hollanders \& Janz, 2014). Thus, the IUS 
offers a more homogenous data set, as European member states are usually culturally closer than states of different continents. The Global Innovation Index (and the Innovation Union Scoreboard) in the regression models constitute for the dependent variable.

As measures for cultural tightness/looseness, the tightness score of Gelfand et al. (2011a), and the cultural tightness-looseness combination index of $\mathrm{Uz}$ (2015a), respectively, are used. In the regression models, these indicators are applied as independent variables.

Due to the composition of the respective indices-indices for tightness/looseness, as well as index for innovativeness-index values stand for ordinal scales. Hence, in a first step, we used rank correlations to detect links between cultural values and innovativeness. These rank correlations measure the relationship between rankings of different ordinal variables. The correlation coefficient in these cases indicates for the degree of similarity between rankings of two variables, and is used to assess the significance of the relation between the variables. In our case, we use Spearman's rho test.

Nonetheless, in particular as the number of groups is very high, there are no general reservations regarding the application of regression models that are usually used for metric data (Zumbo \& Zimmerman, 1993). Hence, in later stages of our empirical strategy we treat the variables as metric for correlation analysis, factor analysis, and regression analysis.

The regressions apply a Generalized Linear Model with a log link. This model fits a link between one or a vector of explanatory variables (and sometimes also one or a vector of control variables), and a dependent variable. In our case, the independent variables are the indices for tightness/looseness as delineated above, while the dependent variable is national innovativeness, measured in GII (as well as other specifications for robustness checks). The regression coefficient displayed in such models- $\operatorname{Exp}(B)-$ cannot be interpreted as in linear Ordinary Least Square regressions, but indicates for the odd ratio that innovativeness measured in GII increases once the respective independent variable increases. ${ }^{9}$

\section{Results}

As can be drawn from Table 1, there is a high, positive and statistically significant (1\% level) correlation between the Global Innovation Index and the rank cultural tightnesslooseness combination index. This is in line with the findings of $\mathrm{Uz}$ (2015a) for data from 2007 that the combination index is positively correlated to innovation as measured by the Global Innovation Index (Uz, 2015b).

As for the correlation using the rank of the tightness score and the rank of the Global Innovation Index, see Table 2, a slightly negative, but insignificant correlation can be stated.

As can be drawn from Table 3, these results hold also for correlation analysis using not the ranks, but the metric values. As for the cultural tightness-looseness combination index, a significant and positive correlation with the Global Innovation Index exists.

${ }^{9}$ Thus, a coefficient $\operatorname{Exp}(B)>1$ stands for a positive impact, while $\operatorname{Exp}(B)<1$ stands for a negative impact. 
Table 1 Correlation ranks data Uz

\begin{tabular}{llc}
\hline & Rank CTL_C & Rank GII \\
\hline $\begin{array}{l}\text { Spearman's rho } \\
\text { Rank CTL_C }\end{array}$ & & \\
Correlation coefficient & 1.000 & $.603^{* * *}$ \\
Sig. (2-tailed) & 64 & .000 \\
$N$ & & 64 \\
Rank Gll & $.603^{* * *}$ & 1.000 \\
Correlation coefficient & .000 & \\
Sig. (2-tailed) & 64 & 64 \\
N & & \\
\hline
\end{tabular}

Source: Authors' estimate

${ }^{* * *}$ Correlation is significant at the 0.01 level (2-tailed)

Table 2 Correlations ranks data Gelfand et al.

\begin{tabular}{lll}
\hline & Rank TS & Rank GII \\
\hline $\begin{array}{l}\text { Spearman's rho } \\
\text { Rank TS }\end{array}$ & & \\
$\quad$ Correlation coefficient & 1.000 & -.023 \\
Sig. (2-tailed) & & .902 \\
$N$ & 32 & 32 \\
Rank Gll & -.023 & 1.000 \\
Correlation coefficient & .902 & 32 \\
Sig. (2-tailed) & 32 & 32 \\
N & & \\
\hline
\end{tabular}

Source: Authors' estimate

${ }^{* * *}$ Correlation is significant at the 0.01 level (2-tailed)

The correlation between the tightness looseness score and the Global Innovation Index remains insignificant, but is negative also applying the metric measures (see Table 4).

A hierarchical factor analysis supports our findings. As can be drawn from Fig. 1, two groups of countries can be differentiated between-countries with a high level of innovativeness and a high degree of looseness, and countries with a low level of both innovativeness and looseness, thus a high tightness. This substantiates the hypothesis that there is a close link between the concepts.

Based on these findings, taking into consideration the methodological caveats as discussed above, we apply regression models on the respective variables. As for this step of our empirical strategy, the following picture can be drawn: we find the following significant positive impact of the cultural tightness-looseness index (CTL_C) on national Innovativeness, while there is a slightly negative, non-significant impact of the tightness score on national innovativeness (see Table 5).

Summing up, scrutinizing the outcomes as delineated above, we find some empirical support for our general hypothesis that there is a negative link between cultural tightness and innovativeness. Hypothesis 1 -cultural tightness has a negative relation to national innovativeness, and conversely cultural looseness has a positive relation to national innovativeness, respectively-is supported by our empirical findings. 
Table 3 Correlation data Uz

\begin{tabular}{|c|c|c|c|c|}
\hline & CTL_C & GII & $\begin{array}{l}\text { GII } \\
\text { SUB-Index input }\end{array}$ & $\begin{array}{l}\text { GII } \\
\text { SUB-Index output }\end{array}$ \\
\hline \multicolumn{5}{|l|}{ CTL_C } \\
\hline Pearson correlation & 1 & $.598^{* * *}$ & $.623^{* * *}$ & $.545^{* * *}$ \\
\hline Sig. (2-tailed) & & .000 & .000 & .000 \\
\hline$N$ & 64 & 64 & 64 & 64 \\
\hline \multicolumn{5}{|l|}{ Gll } \\
\hline Pearson correlation & $.598^{* * *}$ & 1 & $.973^{* * *}$ & $.976^{* * *}$ \\
\hline Sig. (2-tailed) & .000 & & .000 & .000 \\
\hline N & 64 & 64 & 64 & 64 \\
\hline \multicolumn{5}{|l|}{$\begin{array}{l}\text { Gll } \\
\text { SUB-Index input }\end{array}$} \\
\hline Pearson correlation & $.623^{* * *}$ & $.973^{* * *}$ & 1 & $.899^{* * *}$ \\
\hline Sig. (2-tailed) & .000 & .000 & & .000 \\
\hline$N$ & 64 & 64 & 64 & 64 \\
\hline \multicolumn{5}{|l|}{$\begin{array}{l}\text { GII } \\
\text { SUB-Index output }\end{array}$} \\
\hline Pearson correlation & $.545^{* * *}$ & $.976^{* * *}$ & $.899^{* * *}$ & 1 \\
\hline Sig. (2-tailed) & .000 & .000 & .000 & \\
\hline$N$ & 64 & 64 & 64 & 64 \\
\hline
\end{tabular}

Source: Authors' estimate

${ }^{* * *}$ Correlation is significant at the 0.01 level (2-tailed)

Table 4 Correlations data Gelfand et al.

\begin{tabular}{|c|c|c|c|c|}
\hline & CTL & GII & $\begin{array}{l}\text { GII } \\
\text { SUB-Index input }\end{array}$ & $\begin{array}{l}\text { GII } \\
\text { SUB-Index output }\end{array}$ \\
\hline \multicolumn{5}{|l|}{ CTL } \\
\hline Pearson correlation & 1 & -.145 & -.079 & -.199 \\
\hline Sig. (2-tailed) & & .429 & .667 & .274 \\
\hline$N$ & 32 & 32 & 32 & 32 \\
\hline \multicolumn{5}{|l|}{ G॥ } \\
\hline Pearson correlation & -.145 & 1 & $.952^{* * *}$ & $.952^{* * *}$ \\
\hline Sig. (2-tailed) & .429 & & .000 & .000 \\
\hline$N$ & 32 & 32 & 32 & 32 \\
\hline \multicolumn{5}{|l|}{$\begin{array}{l}\text { GII } \\
\text { SUB-Index input }\end{array}$} \\
\hline Pearson correlation & -.079 & $.952^{* * *}$ & 1 & $.813^{* * *}$ \\
\hline Sig. (2-tailed) & .667 & .000 & & .000 \\
\hline$N$ & 32 & 32 & 32 & 32 \\
\hline \multicolumn{5}{|l|}{$\begin{array}{l}\text { GII } \\
\text { SUB-Index output }\end{array}$} \\
\hline Pearson correlation & -.199 & $.952^{* * *}$ & $.813^{* * *}$ & 1 \\
\hline Sig. (2-tailed) & .274 & .000 & .000 & \\
\hline$N$ & 32 & 32 & 32 & 32 \\
\hline
\end{tabular}

Source: Authors' estimate

${ }^{* * *}$ Correlation is significant at the 0.01 level (2-tailed) 


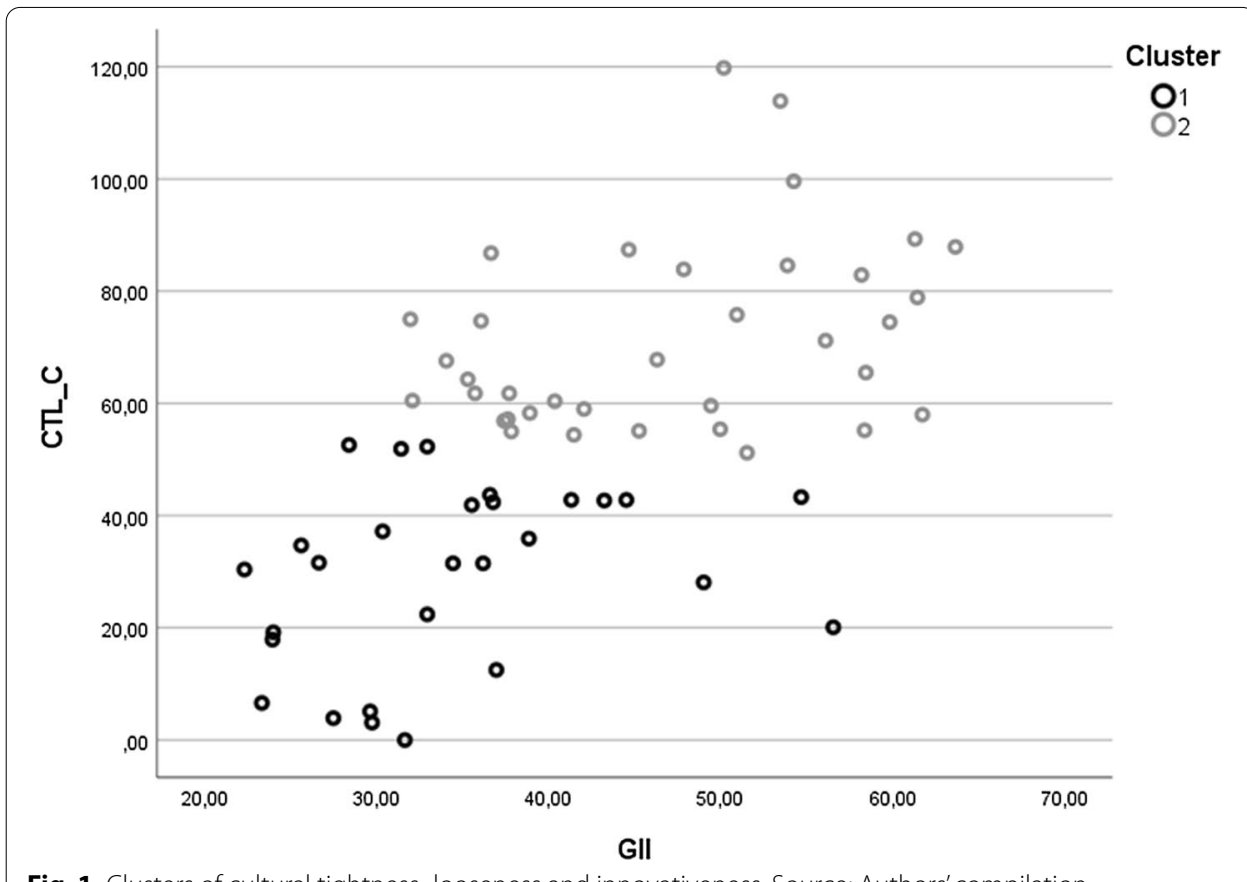

Fig. 1 Clusters of cultural tightness-looseness and innovativeness. Source: Authors' compilation

Table 5 Regression data Uz and Gelfand

\begin{tabular}{lll}
\hline Variable & \multicolumn{1}{|c|}{$\operatorname{Exp}(\boldsymbol{b})$} & \\
\cline { 2 - 3 } & GII 2019 & GII 2019 \\
\hline Intercept & $30.029(.0666)^{* * * *}$ & $51.692(.0808)^{* * * *}$ \\
CTL_C & $1.006(.0010)^{* * *}$ & $.991(.0115)^{* * *}$ \\
TS & & 32 \\
$N$ & 64 & 32 \\
\hline
\end{tabular}

Source: Authors' estimate

*** Significant at $1 \%$ level

In detail, Hypothesis 1.1-tightness as measured by Gelfand et al. (2011a) is affecting national innovativeness negatively-has to be rejected due to the missing significance. Nonetheless, while the respective coefficient remains insignificant, the algebraic sign is negative, indicating for a negative relation between tightness and innovativeness.

Secondly, Hypothesis 1.2-looseness as measured via the cultural tightness-looseness combination index of Uz (2015a) has a positive relation to national innovativeness-is supported by our empirical findings: as can be drawn from Table 3, there is a positive, statistically significant impact of the cultural tightness-looseness on national innovativeness, even if the respective coefficient is relatively small. Accordingly, an increase of looseness measured in the cultural tightness-looseness enhances the odd ratio of an increase of the innovativeness. ${ }^{10}$

\footnotetext{
${ }^{10}$ Due to the nature of the data-innovativeness scores were measured chronologically later than the cultural scoredand additional tests, a potential "reverse causality" can be neglected. Likewise, biases caused by "omitted variables" that influences both, innovativeness and the cultural features, are not impossible, but unlikely. As cultural values and characteristics are a relatively stable trait, influencing factors would have to be rooted at least partly in the ancient history of the respective country, while the actions and policies as measured in the innovation indices (independent variables) were implemented only recently; thus, heterogeneity is unlikely to occur.
} 
Table 6 Regression Rank Global Innovation Index

\begin{tabular}{ll}
\hline Variable & $\begin{array}{l}\text { Exp(b) } \\
\text { Rank GII }\end{array}$ \\
\hline Intercept & $105.811(.1048)^{* * *}$ \\
CTL_C & $.985(.0025)^{* * *}$ \\
$N$ & 64 \\
\hline
\end{tabular}

Source: Authors' estimate

${ }^{* * *}$ Significant at $1 \%$ level

Table 7 Regression Global Innovation Index 2014

\begin{tabular}{llll}
\hline Variable & \multicolumn{1}{|c|}{$\operatorname{Exp}(\boldsymbol{b})$} & \\
\cline { 2 - 4 } & GII 2014 & GII 2014 & GII 2014 \\
\hline Intercept & $30.846(.0628)^{* * *}$ & $15.855(.0387)^{* * *}$ & $17.947(.0348)^{* * *}$ \\
CTL_C & $1.004(.0009)^{* * *}$ & & \\
Innovation input Sub-Index score & & $1.020(.0007)^{* * *}$ & \\
Innovation output Sub-Index score & & & $1.023(.0008)^{* * *}$ \\
$N$ & 64 & 64 & 64 \\
\hline
\end{tabular}

Source: Authors' estimate

${ }^{* * *}$ Significant at $1 \%$ level

For robustness checks, we tested different alternative specifications of national innovativeness, e.g., the Rank Global Innovation Index (values for 2019), data from the Global Innovation Index for 2014, and the IUS Summary Innovation Index for 2013.

As the ranks used for the estimations as shown in Table 6 are inverted-with least innovative countries showing high ranks-the negative impact of looseness indicates for the causal relation as assumed.

As can be drawn from Tables 7 and 8, the outcome using the Global Innovation Index 2014 and the IUS Summary Innovation Index 2013 as the dependent variable more or less replicate our findings as delineated above, indicating for a high level of robustness of our findings.

\section{Discussion}

As expected following our theoretical delineations, a significant positive relation between cultural looseness-as measured by Uz (2015a) —on national innovativeness exists. Nonetheless, these finding due to missing significance do not hold for the data as provided by Gelfand et al. (2011a). Even if methodological restrictions do not allow us to make a clear-cut statement about a causal relationship, we assume the link not being coincidental, but causal by nature. Further research applying more control variables to an adjusted data base may shed light on this. Overall, we can conclude that our working hypothesis is sufficiently underpinned by the outcomes of the different models and specifications using the cultural tightness-looseness index, so that we can assume this positive relation between innovativeness and cultural looseness being real.

Nonetheless, we have to take a deeper look on the non-significant results. Scrutinizing the disparate methodological approaches applied in the indices, one plausible assumption is that the missing significance in the models using the indicator as 
Table 8 Regression IUS Summary Innovation Index 2013

\begin{tabular}{ll}
\hline Variable & $\begin{array}{l}\operatorname{Exp}(\boldsymbol{b}) \\
\text { IUS Summary } \\
\text { Innovation } \\
\text { Index }\end{array}$ \\
\hline Intercept & $.248(.1550)^{* * *}$ \\
CTL_C & $1.009(.0019)^{* * *}$ \\
N 30 & \\
\hline
\end{tabular}

Source: Authors' estimate

${ }^{* * *}$ Significant at $1 \%$ level

provided by Gelfand et al. (2011a) can be explained by methodological differences in indicator construction, compared to $\mathrm{Uz}$ (2015a).

First, there is a significant difference in the number of surveyed countries. Gelfand et al. (2011a) include data from 33 nations, while the cultural tightness-looseness combination index by Uz (2015a) is based on data from 65 nations. Furthermore, there is not a complete overlap of countries, as about $30 \%$ of the countries in the study by Gelfand et al. (2011a) are not included in the study by Uz (2015a).

Second, there are differences in the sampling of data within the covered nations. Sampling of data is a critical issue as there are not only national differences of tightness-looseness (Chan et al., 1996; Gelfand et al., 2011a; Uz, 2015a), but also regional differences within nations (Chua et al., 2019; Harrington \& Gelfand, 2014; Uz, 2016). The World Values Survey (WVSA, 2020) used by Uz (2015a) usually has sample sizes of between 1000 and 1500 respondents per country. The main distributions of the samples are according to country characteristics such as percentage of urban and rural population. Gelfand et al. (2011a) have sample sizes between 111 and 312 respondents per country, and respondents are exclusively from the urban population. A focus on urban population could lead to a bias in answers, as people from rural areas are typically tighter than people from urban areas (Triandis, 1989).

Third, there are differences in measurement. Gelfand et al. (2011a) use primary data, i.e., they directly ask people about the tightness in their respective societies, while Uz (2015a) uses secondary data from the WVS and indirectly infers the tightness via the variance of answers. Uz (2015a) criticizes that Gelfand et al. (2011a) do not measure tightness, but rather perception of tightness. The different procedures imply that Gelfand et al. (2011a) use a measure of central tendencies (mean value), while Uz (2015a) uses a measure of spread (standard deviation). Furthermore, Gelfand et al. (2011b) only ask questions about tolerance for norms in general. As there is a "discrepancy between the principle and the practice of tolerance" (van Doorn, 2012: 6), there is typically an inconsistency between general norms people claim to abide by and specific norms people apply with regard to controversial issues. This means that self-assessment of general tolerance is typically higher than selfassessment of specific tolerance, especially for controversial issues. Questions on specific tolerance regarding controversial issues such as religion, political views and sexual orientation are included in the WVS used by Uz (2015a). All in all, it could be argued that the answers in the study of Gelfand et al. (2011a) are expected to 
be biased towards looseness due to the focus on urban population and on general tolerance.

Scrutinizing these considerations and the fact that a larger sample usually provides better results in empirical research, we can plausibly assume that the data sample used by $\mathrm{Uz}$ (2015a) provides not only a higher sample quality due to the additional variance of countries and aspects covered, but also a better basis for estimation models.

Hence, coming to terms with the interpretation of our results, we only observe a significant positive relation to innovativeness when tightness-looseness is measured as a spread of norms as in the study of Uz (2015a). This indicates that pluralism or diversity of opinions in a society is conducive to innovativeness. However, loose culture does not mean a high individual tolerance in general, but rather the endurance of low and high specific tolerance of controversial issues within an open society.

Our results on the role of diversity on the societal level is in line with studies tackling the macro-level with regard to economic development (Alesina et al., 2003; Gören, 2014; Montalvo \& Reynal-Querol, 2005), as well as the meso- and microlevel, focusing on creativity and innovation with regard to regional units or teams. Cultural and functional diversity in teams have a positive impact on creativity (Paulus et al., 2012, 2016; Reiter-Palmon et al., 2012; Stollberger et al., 2019). However, team diversity needs to be balanced by participatory safety to strengthen team identity and increase the receptiveness for different individual perspectives (Deckert, 2019). Likewise, for urban regions there is evidence that a diverse and heterogeneous region will attract more creative people, accelerates knowledge diffusion, and leads to a higher rate of innovation and ultimately economic growth (Florida, 2004). Diverse societal norms, values and ethics can induce technological innovation and the diffusion of new ideas, "heterogeneity improves problem-solving" and "heterogeneous groups of people with limited abilities can do better than homogeneous groups of high-ability problem-solvers" (Bove \& Elia, 2017: 228; also Ager \& Brückner, 2013, Ottaviano \& Peri, 2006).

Hence, while diversity can lead to more conflict, on the micro- as well as the macro-level (Alesina \& La Ferrara, 2005; Esteban \& Ray, 2011; Montalvo \& ReynalQuerol, 2005), it also can enhance creativity, if it is a disagreement about the related task (task conflict), solved in a constructive way, and of low intensity (Paulus et al., 2012, 2016; Reiter-Palmon et al., 2012; Stollberger et al., 2019). Hence, if managed constructively, diversity is an asset for innovativeness more than an obstacle.

\section{Conclusion}

Applying correlation analysis, factor analysis and regression analyses, we were able to show that loose cultures on average display a higher national innovativeness, with cultural looseness having a positive link to innovativeness. Nonetheless, this significant positive link between looseness on national innovativeness only holds when tightnesslooseness is measured as a spread of norms following $\mathrm{Uz}$ (2015a). 
At this point, we draw to the reflections by Koestler (1967) who calls humans "social holons"-a term derived from the Greek word "holos" for whole, and the suffix "on", typically assigned to parts (as in proton). A "social holon" features a tension between the preservation of its individuality and the integration into a larger unit (e.g., family, nation), respectively. Understood in this way, different cultures position themselves on different spots along the continuum between preservation (individualism) and integration (collectivism). In this framework, cultural tightness as measured by Uz (2015a) signifies how clearly this spot can be determined, i.e., if every individual in a society agrees on one spot (tight and homogeneous), or if people in a society can inhabit different spots (loose and heterogeneous).

With regard to innovativeness, we find that it is pluralism or diversity of opinions on specific controversial issues in a society rather than high individual tolerance that fosters innovation. This implies that it is not only necessary to give freedom to the individual, as John Stuart Mill (2002: 69) argues when he says that "it is important to give the freest scope possible to uncustomary things, in order that it may in time appear which of these are fit to be converted into customs". Moreover, it is necessary to have culture-specific norms as guiding principles, as Haidt (2013: 359) reasons: "We need groups, we love groups, and we develop our virtues in group, even though those groups necessarily exclude nonmembers". This dichotomy is the inherent paradox in the concept of looseness of Uz (2015a), and thus in the mechanisms fostering innovativeness. The knack seems to be the capacity of a society to simultaneously endure groups with different degrees of tolerance towards controversial issues and to manage the peaceful exchange between these groups. It is looseness in this sense that is conducive to innovativeness.

\section{Appendix}

\section{Appendix 1: Summary statistics}

Data Uz

\begin{tabular}{llllll}
\hline & N & Minimum & Maximum & Mean & Standard deviation \\
\hline CTL_C & 64 & .00 & 119.80 & 53.1141 & 26.56960 \\
GII & 64 & 22.30 & 63.65 & 41.5083 & 11.29005 \\
GII & 64 & 29.22 & 72.15 & 50.1927 & 11.29187 \\
SUB-Index Input & & & & & \\
GII & 64 & 13.32 & 57.49 & 32.8173 & 11.88716 \\
SUB-Index Output & & & & & \\
Rank CTL_C & 64 & 1.0 & 64.0 & 32.500 & 18.6183 \\
Rank GII & 64 & 1.0 & 64.0 & 32.500 & 18.6188 \\
Rang GII & 64 & 1 & 64 & 32.50 & 18.619 \\
SUB-Index Input & & & & & \\
Rang GII & 64 & 1 & 64 & 32.50 & 18.6186 \\
SUB-Index Output & & & & & \\
\hline
\end{tabular}


Data Gelfand

\begin{tabular}{lcclcl}
\hline & N & Minimum & Maximum & Mean & Standard deviation \\
\hline CTL & 32 & 1.6 & 12.3 & 6.578 & 2.7862 \\
GII & 32 & 25.36 & 61.73 & 48.7263 & 9.24454 \\
GII & 32 & 31.26 & 72.15 & 57.5775 & 9.75359 \\
SUB-Index Input & & & & & \\
GII & 32 & 19.10 & 57.49 & 39.8641 & 9.69809 \\
SUB-Index Output & & & & & \\
Rank CTL & 32 & 1.0 & 32.0 & 16.500 & 9.3783 \\
Rank GII & 32 & 1.0 & 32.0 & 16.500 & 9.3800 \\
Rank GII & 32 & 1.0 & 32.0 & 16.500 & 9.3800 \\
SUB-Index Input & & & & & \\
Rank GII & 32 & 1.0 & 32.0 & 16.500 & 9.3800 \\
SUB-Index Output & & & & & \\
\hline
\end{tabular}

\section{Appendix 2: List of countries Gelfand et al.}

\begin{tabular}{ll}
\hline Australia & Mexico \\
Austria & Netherlands \\
Belgium & New Zealand \\
Brazil & Norway \\
Estonia & Pakistan \\
France & People's Republic of China \\
Germany (former East) & Poland \\
Germany (former West) & Portugal \\
Greece & Singapore \\
Hong Kong & South Korea \\
Hungary & Spain \\
Iceland & Turkey \\
India & Ukraine \\
Israel & United Kingdom \\
Italy & United States \\
Japan & Venezuela \\
Malaysia & \\
\hline
\end{tabular}




\section{Appendix 3: List of countries Uz}

\begin{tabular}{ll}
\hline Albania & Luxembourg \\
Algeria & Macedonia \\
Argentina & Malta \\
Austria & Mexico \\
Bangladesh & Moldavia \\
Belarus & Morocco \\
Belgium & Northern Ireland \\
Bosnia and Herzegovina & Netherlands \\
Bulgaria & Nigeria \\
Canada & Pakistan \\
Chile & Peru \\
China & Philippines \\
Croatia & Poland \\
Czech Republic & Portugal \\
Denmark & Puerto Rico \\
Egypt & Romania \\
Estonia & Russian Federation \\
Finland & Saudi Arabia \\
France & Serbia \& Montenegro \\
Germany & Singapore \\
Great Britain & Slovakia \\
Greece & Slovenia \\
Hungary & South Africa \\
Iceland & South Korea \\
India & Spain \\
Indonesia & Sweden \\
Iran & Tanzania \\
Ireland & Turkey \\
Italy & Uganda \\
Japan & Ukraine \\
Jordan & United States of America \\
Kyrgyzstan & Venezuela \\
Latvia & Vietnam \\
Lithuania & Zimbabwe \\
\hline & \\
\hline
\end{tabular}

Appendix 4: Data for index construction by $\mathrm{Uz}$

\begin{tabular}{|c|c|c|}
\hline Index & No. of countries ${ }^{1}$ & Questions included $^{2}$ \\
\hline Domain specific index & 68 (without Iraq and Israel) & $\begin{array}{l}\text { WVS, Wave 4, Card W (Morally Debatable } \\
\text { Behavior Scale, MDBS): V204, V206, V207, } \\
\text { V209, V210, V211, V212, V213 }\end{array}$ \\
\hline Domain general index & $\begin{array}{l}64 \text { (without China, Iraq, Israel, Saudi Ara- } \\
\text { bia, Singapore and Venezuela) }\end{array}$ & WVS, Wave 4, all Cards ${ }^{3}$ \\
\hline Combination index & $\begin{array}{l}65 \text { (without China, Iraq, Israel, Pakistan and } \\
\text { Venezuela) }\end{array}$ & $\begin{array}{l}\text { WVS, Wave 4, Card C (work), Card D (family), } \\
\text { Card E (politics) and Card F (religion) } \\
\text { Card A (importance of domains) used as a } \\
\text { weight }\end{array}$ \\
\hline
\end{tabular}

Explanatory notes:

WVS: World Values Survey (https://www.worldvaluessurvey.org/wvs.jsp).

${ }^{1}$ Countries which answered more than $90 \%$ of relevant questions $(n=70)$.

${ }^{2}$ Questions from the respective Cards that have been asked in $90 \%$ of the countries.

3"These 124 values and behaviors asked across countries include what is important in life, child rearing values, ways of spending leisure time, tolerance for different people, moral values, work values, family values, gender roles, politics, democracy, opinions about different formal and informal intuitions [sic], religion and religious beliefs/ behavior, feelings of belonging and national identity" (Uz, 2015b, p. 2). 


\section{Abbreviations}

CTL_C: Cultural tightness-looseness combination index; Gll: Global Innovation Index; TS: Tightness score.

\section{Acknowledgements}

None.

\section{Authors' contributions}

The theoretical framework was developed by both authors, with CD being the leading author in this part, the empirical research was mainly conducted by RMS. Both authors read and approved the final manuscript.

\section{Funding}

Open Access funding enabled and organized by Projekt DEAL. The project is funded under the program of the Minister of Science and Higher Education Poland titled "Regional Initiative of Excellence" in 2019-2022, project number 018/ RID/2018/19, the amount of funding PLN 10788 423,16.

\section{Availability of data and materials}

The data will be made accessible upon request.

\section{Declarations}

\section{Competing interests}

Non competing interests have to be stated.

\section{Author details}

${ }^{1}$ WSB University, Dabrowa Gornicza, Poland. ${ }^{2}$ Hochschule Duesseldorf University of Applied Sciences (HSD), Düsseldorf, Germany.

Received: 12 January 2021 Accepted: 12 January 2022

Published online: 05 March 2022

\section{References}

Acemoglu, D., Johnson, S., \& Robinson, J. A. (2005). Institutions as a fundamental cause of long-run growth. In P. Aghion \&

S. N. Durlauf (Eds.), Handbook of economic growth (Vol. IA, pp. 385-471). Elsevier.

Acemoglu, D., \& Robinson, J. A. (2013). Why nations fail: The origins of power, prosperity and poverty. Profile Books.

Adam, F. (2013). Measuring national innovation performance. Springer.

Ager, P., \& Brückner, M. (2013). Cultural diversity and economic growth: Evidence from the US during the age of mass migration. European Economic Review, 64, 76-97.

Alesina, A., Devleeschauwer, A., Easterly, W., Kurlat, S., \& Wacziarg, R. (2003). Fractionalization. Journal of Economic Growth, $2,155-194$.

Alesina, A., \& La Ferrara, E. (2005). Ethnic diversity and economic performance. Journal of Economic Literature, 43, 762-800.

Bove, V., \& Elia, L. (2017). Migration, diversity, and economic growth. World Development, 89, 227-239.

Bridges, C. C., Jr. (1966). Hierarchical cluster analysis. Psychological Reports, 18(3), 851-854.

Carpenter, S. (2000). Effects of cultural tightness and collectivism on self-concept and causal attributions. Cross-Cultural Research, 1, 38-56.

Chan, D. K. S., Gelfand, M. J., Triandis, H. C., \& Tzeng, O. (1996). Tightness-looseness revisited: some preliminary analyses in Japan and the United States. International Journal of Psychology, 1, 1-12.

Chua, R. Y. J., Huang, K. G., \& Jin, M. (2019). Mapping cultural tightness and its links to innovation, urbanization, and happiness across 31 provinces in China. Proceedings of the National Academy of Sciences, 14, 6720-6725. https://doi.org/10. 1073/pnas.1815723116

Cornell University, INSEAD, WIPO. (2019). Global Innovation Index 2019: Creating healthy lives-The future of medical innovation. Geneva, Ithaca, and Fontainebleau.

Deckert, C. (2019). Tensions in team creativity. Using the value square to model team climate for creativity (Working paper in Industrial Engineering, No. 1). Düsseldorf, University of Applied Sciences.

Deckert, C., \& Nyssen Guillén N. (2017). VI. Kulturelle Einflüsse auf die nationale Innovationsfähigkeit - Zusammenhang zwischen den Hofstede-Dimensionen und dem Innovationsindex Gll [Cultural impacts on national innovativeness-Relationship between Hofstede dimensions and the Innovation Index GII]. WiSt - Wirtschaftswissenschaftliches Studium 201, 7-8, 25-31.

Deckert, C., \& Schomaker, R. M. (2018). Cultural impacts on national innovativeness: Not every cultural dimension is equal. Cross-Cultural Research, 2, 186-214. https://doi.org/10.1177/1069397118799700

Esteban, J., \& Ray, D. (2011). Linking conflict to inequality and polarization. American Economic Review, 4, 1345-1374.

Florida, R. (2004). The rise of the creative class. Basic Books.

Freeman, C. (1995). The 'national system of innovation' in historical perspective. Cambridge Journal of Economics, 19, 5-24.

Freeman, C. (2002). Continental, national and sub-national innovation systems-Complementary and economic growth. Research Policy, 31, 191-211.

Freeman, C., \& Soete, L. (1997). The economics of industrial innovation (3rd ed.). MIT Press.

Freeman, J. (1996). Innovation and growth. In M. Dodgson \& R. Rothwell (Eds.), The handbook of industrial innovation (pp. 78-93). Edgar Elgar.

Furman, J. L., Porter, M., \& Stern, S. (2002). The determinants of national innovative capacity. Research Policy, 31, 899-933. 
Gault, F. (2014). The Oslo manual. In F. Gault (Ed.), Handbook of innovation indicators and measurement (pp. 41-59). Edward Elgar.

Gelfand, M. J. (2012). Culture's constraints: International differences in the strength of social norms. Current Directions in Psychological Science, 6, 420-424. https://doi.org/10.1177/0963721412460048

Gelfand, M. J. (2018). Rule makers, rule breakers: How tight and loose cultures wire our world. Robinson.

Gelfand, M. J., Harrington, J. R., \& Jackson, J. C. (2017). The strength of social norms across human groups. Perspectives on Psychological Science, 5, 800-809. https://doi.org/10.1177/1745691617708631

Gelfand, M. J., \& Jackson, J. C. (2016). From one mind to many: The emerging science of cultural norms. Current Opinion in Psychology, 8, 175-181. https://doi.org/10.1016/j.copsyc.2015.11.002

Gelfand, M. J., Nishii, L. H., \& Raver, J. L. (2006). On the nature and importance of cultural tightness-looseness. Journal of Applied Psychology, 6, 1225-1244. https://doi.org/10.1037/0021-9010.91.6.1225

Gelfand, M. J., Raver, J. L., Nishii, L., Leslie, L. M., Lun, J., Lim, B. C., Duan, L., Almaliach, A., Ang, S., Arnadottir, J., Aycan, Z., Boehnke, K., Boski, P., Cabecinhas, R., Chan, D., Chhokar, J., D’Amato, A., Ferrer, M., Fischlmayr, I. C., \& Yamaguchi, S. (2011a). Differences between tight and loose cultures: A 33-nation study. Science, 6033, 1100-1104. https://doi. org/10.1126/science.1197754

Gelfand, M. J., Raver, J. L., Nishii, L., Leslie, L. M., Lun, J., Lim, B. C., Duan, L., Almaliach, A., Ang, S., Arnadottir, J., Aycan, Z., Boehnke, K., Boski, P., Cabecinhas, R., Chan, D., Chhokar, J., D'Amato, A., Ferrer, M., Fischlmayr, I. C., \& Yamaguchi, S. (2011 b). Supporting online material for differences between tight and loose cultures: A 33-nation study. Retrieved April 09, 2020 from www.sciencemag.org/cgi/content/full/332/6033/1100/DC1.

Gören, E. (2014). How ethnic diversity affects economic growth. World Development, 59, 275-297.

Haidt, J. (2013). The righteous mind. Why good people are divided by politics and religion. Penguin.

Harrington, J. R., \& Gelfand, M. J. (2014). Tightness-looseness across the 50 united states. Proceedings of the National Academy of Sciences, 22, 7990-7995. https://doi.org/10.1073/pnas.1317937111

Higgins, T. E. (1997). Beyond pleasure and pain. American Psychologist, 12, 1280-1300.

Higgins, T. E. (1998). Promotion and prevention: Regulatory focus as a motivational principle. In M. P. Zanna (Ed.), Advances in experimental social psychology (Vol. 30, pp. 1-46). Academic Press.

Hofstede, G. H. (2003). Culture's consequences: Comparing values, behaviors, institutions and organizations across nations (2nd ed.). Sage Publications.

Hollanders, H., \& Janz, N. (2014). Scoreboards and indicator reports. In F. Gault (Ed.), Handbook of innovation indicators and measurement (pp. 279-300). Edward Elgar.

House, R. J., Hanges, P. J., Javidan, M., Dorfmann, P. W., \& Gupta, V. (2004). Culture, leadership, and organizations: The Globe Study of 62 societies. Sage Publications.

House, R. J., Javidan, M., Hanges, P., \& Dorfman, P. (2002). Understanding culture and implicit leadership theories across the globe: An introduction to project GLOBE. Journal of World Business., 37(2002), 3-10.

Kirton, M. J. (1989). A theory of cognitive style. In M. J. Kirton (Ed.), Adaptors and innovators. Styles of creativity and problem-solving. Routledge.

Koestler, A. (1967). The ghost in the machine. Picador.

Kumar, V. (2014). Understanding cultural differences in innovation: A conceptual framework and future research directions. Journal of International Marketing, 3, 1-29.

Landes, D. (2002). The wealth and poverty of nations. Abacus.

Lubart, T. (2010). Cross-cultural perspectives on creativity. In J. C. Kaufman \& R. J. Sternberg (Eds.), The Cambridge handbook of creativity (pp. 265-278). Cambridge University Press.

Lundvall, B. A. (1999). National Business Systems and National Systems of Innovation. International Journal of Management \& Organisation, 2, 60-77.

Mill, J. S. (2002). The basic writings of John Stuart Mill. Modern Library.

Montalvo, J. G., \& Reynal-Querol, M. (2005). Ethnic diversity and economic development. Journal of Development Economics, 2, 293-323.

North, D. C. (1991). Institutions. Journal of Economic Perspectives., 5(1), 97-112.

Organisation for Economic Co-operation and Development. (1997). National innovation systems. OECD.

Ottaviano, G. I., \& Peri, G. (2006). The economic value of cultural diversity: Evidence from US cities. Journal of Economic Geography, 1, 9-44.

Paulus, P. B., Dzindolet, M., \& Kohn, N. W. (2012). Collaborative creativity-Group creativity and team innovation. In M. D. Mumford (Ed.), Handbook of organizational creativity (pp. 327-358). Academic Press.

Paulus, P. B., van der Zee, K. I., \& Kenworthy, J. (2016). Cultural diversity and team creativity. In V. P. Glaveanu (Ed.), The Palgrave handbook of creativity and culture research (pp. 57-76). Palgrave.

Pelto, P. J. (1968). The differences between "tight" and "loose" societies. Transaction, 5, 37-40. https://doi.org/10.1007/ BF03180447

Porter, M. E. (1990). The competitive advantage of nations. Harvard Business Review, 3-4, 73-93.

Porter, M. E., \& Stern, S. (2001). Innovation: Location matters. MIT Sloan Management Review, 4, 28-36.

Reiter-Palmon, R., Wigert, B., \& de Vreede, T. (2012). Team creativity and innovation: The effect of group composition, social processes, and cognition. In M. D. Mumford (Ed.), Handbook of organizational creativity (pp. 295-326). Academic Press.

Rogers, M. E. (2003). Diffusion of innovations (5th ed.). Free Press.

Schomaker, R. M., \& Deckert, C. (2020). Wachstum, Entwicklung und Governance: Zur Interdependenz von Regierungsführung und wirtschaftlicher Entwicklung [Growth, Development and Governance: About the Interdependence of Governance and Economic Development]. In Leschke, M., Otter, N. (Hrsg.), Wachstum und Entwicklung: Globale Instabilitäten und neue wirtschaftspolitische Konzepte. München: De Gruyter (Schriftenreihe zu Ordnungsfragen der Wirtschaft; 106).

Stollberger, J., West, M. A., \& Sacramento, C. A. (2019). Group creativity in team and organizational innovation. In P. Paulus \& B. Nijstad (Eds.), The Oxford handbook of group creativity and innovation. Oxford University Press. 
Taylor, M. Z. (2016). The politics of innovation. Why some countries are better than others at science \& technology. Oxford University Press.

Trantow, S., Hees, F., \& Jeschke, S. (2011). Innovative capability—An introduction to this volume. In S. Jeschke, I. Isenhardt, F. Hees, \& S. Trantow (Eds.), Enabling innovation: Innovative capability—German and international views (pp. 1-13). Springer.

Triandis, H. C. (1989). The Self and social behavior in differing cultural contexts. Psychological Review, 3, 506-520.

Triandis, H. C. (1994). Culture and social behavior. McGraw-Hill.

Uz, I. (2015a). The index of cultural tightness and looseness among 68 countries. Journal of Cross-Cultural Psychology, 3, 319-335. https://doi.org/10.1177/0022022114563611

$\mathrm{Uz}$, I. (2015b). Supplementary material for the index of cultural tightness and looseness among 68 countries. Journal of Cross-Cultural Psychology, 3, 319-335. https://doi.org/10.1177/0022022114563611

Uz, I. (2016). Cross-validation of cultural tightness and looseness measures. International Journal of Psychology, 4, 287-294. https://doi.org/10.1002/ijop.12376

van Doorn, M. (2012). Tolerance. Sociopedia.isa. https://doi.org/10.1177/2056846012121

Verspagen, B. (2006). Innovation and economic growth. In J. Fagerberg, D. C. Mowery, \& R. R. Nelson (Eds.), The Oxford handbook of innovation (pp. 487-513). Oxford University Press.

Williams, L. K., \& McGuire, S. J. (2010). Economic creativity and innovation implementation: The entrepreneurial drivers of growth? Evidence from 63 countries. Small Business Economics, 34, 391-412. https://doi.org/10.1007/ s11187-008-9145-7

Witkin, H. A., \& Berry, J. W. (1975). Psychological differentiation in cross-cultural perspective. Journal of Cross-Cultural Psychology, 6, 4-87.

World Values Survey Association. (2020). Methodology. Retrieved April 09, 2020 from http://www.worldvaluessurvey.org/ WVSContents.jsp.

Zumbo, B. D., \& Zimmerman, D. W. (1993). Is the selection of statistical methods governed by level of measurement? Canadian Psychology, 34, 390-399.

\section{Publisher's Note}

Springer Nature remains neutral with regard to jurisdictional claims in published maps and institutional affiliations.

\section{Submit your manuscript to a SpringerOpen ${ }^{\circ}$ journal and benefit from:}

- Convenient online submission

- Rigorous peer review

- Open access: articles freely available online

- High visibility within the field

Retaining the copyright to your article

Submit your next manuscript at $\boldsymbol{\Delta}$ springeropen.com 